\title{
Effects of Social Media Use on Millennials' Perceptions of Community Leaders
}

\author{
Courtney Marie Evans \\ College of Agricultural and Life Sciences, University of Florida
}

Faculty mentor: Cecilia E. Suarez, Department of Agricultural Education and Communication

\begin{abstract}
Acknowledging that social media use is ever growing and increasingly used to communicate with constituents, this article investigates the effect that a community leader's social media activity has on young adults' perceptions of their leadership. The method utilized a qualitative analysis of research related to young adults' relationship with politics juxtaposed to a quantitative analysis of a Qualtrics survey of 106 people between 18 and 24 years of ages' self-evaluated trust of community leaders presence on social media. It illustrates that perception of community leaders is not significantly improved through use of social media.
\end{abstract}

Keywords: social media, community leaders, millennials

\section{Introduction}

In 2018, the Pew Research Center reported that use of social media had grown from 5\% in 2005 to $69 \%$ of the U.S. population in 2018 (Pew Research Center, 2018). As social media grows, the science examining our relationship with social media presence is growing. Pew Research Center also reported that just 3\% of social media users feel they can trust the information that they are reading on these social media platforms (Pew Research Center, 2018). This information is contradictory to a study done by Chang Suk Park that found the use of some social media was positively correlated to political knowledge (Park, 2017). When we look at these two studies, it asks the question of why social media users feel they have political knowledge, yet they also do not trust the information that they are reading.

The relevance of the aforementioned question is made further clear through the results of a comparative study by Vromen, Loader, Xenos, and Bailo on youth political participation on Facebook. Their study found that social media has become a daily source for information about politics and current events for youth (Vromen, Loader, Xenos \& Bailo, 2016). Vromen et al. further found that, while youth did actively post about politics and issues that were important to 
them, the youth did not tend to engage in political debate or discourse on social media. Similarly, a 2016 study by Gottfried, Barthel, Shearer, and Mitchell found that 1/3 of 18-29 year olds noted that social media was the most helpful media to learn about the most recent presidential election (Gottfried, Barthel, Shearer, \& Mitchell, 2016). Most recently, Edgerly, Thorson, and Wells demonstrated that young people overwhelmingly receive political information through social media (Edgerly, Thorson, \& Wells, 2018). Collectively, these articles illustrate the need for more social science research about social media usage and to the extent that opinion is affected by social media posts.

While distrust of social media is abundant, the effects of poor use of social media are felt widespread. There seems to be a growing amount of scandal from social media at the international, national, and local level. From city commissioners sharing controversial memes (Vossler, 2017) to cutting advertising ties over tweets (Breuninger, 2018), this issue of how our community leaders can be embroiled in scandal over social media usage is also prevalent. As Park's research is to Pew Research Center's poll, this information is contradictory to the statement that only $3 \%$ of social media users trust the information they read on social media (Pew Research Center, 2018), yet social media users are willing to vilify their leaders over social media posts. Additionally, the previous studies have established that social media is widely used among youth for political knowledge. Compiled, this information asks the question, what information are social media users trusting? Is the information they trust coming from elsewhere? With these comparisons in mind, this study aims to investigate how these could possibly be related to interacting with community leaders' pages. The ages of 18-24 were selected due to Pew Research Center's polls illustrating the large amount of use that those ages 18-24 have of social media (Pew Research Center, 2018). More specifically, the goal of this research is to discover if and how social media is affecting the perspectives of young people aged 18-24 on their perceptions of leaders in their communities. This paper describes and analyzes previous research to question the relationship between 18-24 year olds and their perception of community leaders' usage of social media and contributes to the literature a quantitative study of 18-24 year olds self-reporting to a Qualtrics survey on how they perceive social media affecting their relationship with their community leaders. Based on the information stated above, we hypothesize that the perception of a community leader will not be improved through use of social media. 


\section{Methodology}

\section{Procedure}

To design the survey, a literature review of two journal articles were compared to Pew Research Center's online publications on social media use amongst those aged 18-24 years old. The first journal article examined was authored by Leticia Bode. Bode concluded that social media has the potential to learn political information; however, the general public does not always accomplish this (Bode, 2016). Bode's research was an important influence in this research because her critical analyses justified the idea that users have the potential to learn from social media. Bode's work also relates critically to Park's assertions that social media use is correlated to greater political knowledge (Park, 2017). Both of these studies used more direct testing of individuals and more complex methods of analyzing data to come to their conclusions; the current study, aims to examine self-reported survey answers on young adult's perceptions of their community leaders to add public opinion to the literature. This is an important aspect because, in future studies, we could juxtapose public opinion with experiments to test what type of political learning is occurring.

The survey was designed with these studies in mind; however, based on the research's focus on political learning and the idea that those not politically inclined may not interact as much, the term 'community leaders' was used to allow for more participants and a broader reach. The social media tool was also left open to interpretation because Pew Research Center's polls essentially reported that this age group uses a lot of the same social media platforms (Pew Research Center, 2018). A copy of the survey is included in the Appendix. A Likert Scale was selected for the multiple-choice answers in order to get a wider breadth of opinion. The options given were strongly agree, agree, neither agree nor disagree, disagree, and strongly disagree. Pie charts were used to illustrate the results to show which answer was selected the most.

\section{Participants}

For this survey, the link was distributed through Facebook, Instagram, Twitter, and Snapchat to reach a diverse group of 18-24 year olds. These platforms were chosen based on Pew Research Center's data that these platforms are primarily used by 18-24 year olds. Participation was completely voluntary. At the conclusion of the survey, there were 113 total responses with 106 of those being between the ages of 18-24. Of those 106,88 were currently attending a college or university. Of those 88, two responses came from students in Ireland, 17 colleges and universities 
were represented, and 7 U.S. states (Pennsylvania, New Hampshire, Massachusetts, Indiana, North Carolina, Georgia, and Florida) were also represented.

\section{Results}

The results of this survey were thought-provoking and did align with what the previous research had stated. Looking at Figure 1, it can be seen that when asked if they felt they could trust community leaders more if they had a social media presence, the majority of participants

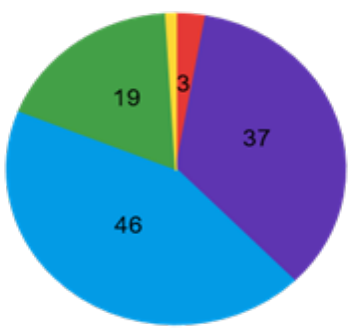

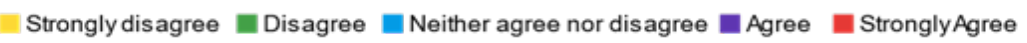

Figure 1. Response to: I trust community leaders who have social media pages more than I would trust a community leader without a social media page.

did not feel that was the case. This harkens back to Pew Research Center's assertion that social media users do not necessarily trust the information that they are reading. With only $40 \%$ agreeing or strongly agreeing with the statement, one wonders of the value of information provided on social media. . When Figure 1 and Figure 5 are juxtaposed which, in order, state that the majority did not feel they could trust a leader more because the leader was on social media, but the responses overwhelmingly agreed that, even on a personal page, if the leader posted something they disagreed with that would be less likely to vote for them in the future. 
In relation, according to Figure 3 and Figure 4, 52\% of respondants stated that social media is their main source of information on their community leaders; however, only $25 \%$ said that they preferred these social media pages to a more traditional website to learn about their leaders. This creates conflict in the results and may suggest further research be executed.

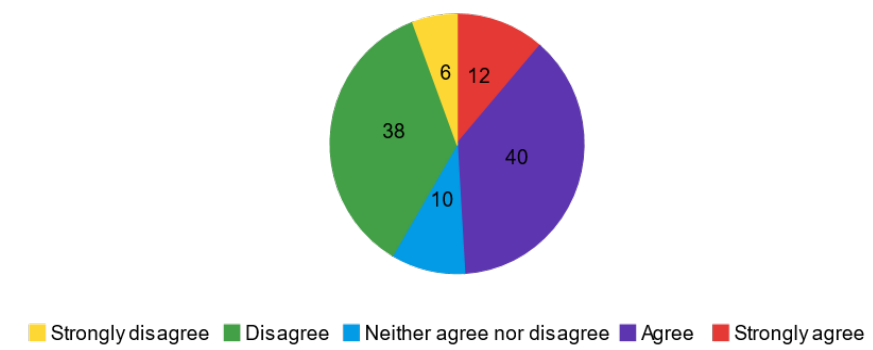

Figure 3. Responses to: Social media is my main source of information on my community leaders.

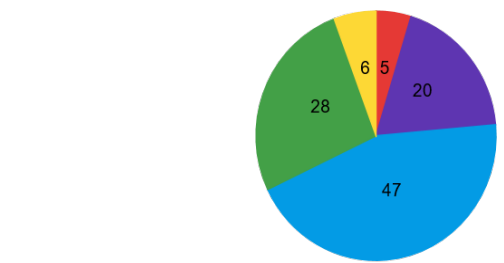

Wtrongly disagree $\square$ Disagree $\square$ Neither agree nor disagree $\square$ Agree $\square$ Stronglyagree

Figure 4. Responses to: I prefer my community leaders to have social media sites instead of websites.

While $69 \%$ of responses either agreed or strongly agreed that they felt more connected to their leaders that had social media pages, only $24 \%$ of responses claimed that they actively engage with these leaders, as seen in Figure 5 and Figure 6. This questions the assertion that social media is a tool for democratic discourse because it is obvious that the majority of users are not actively engaging in the discussion.

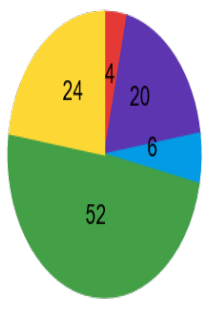

Strongly disagree Disagree Neither agree nor disagree Agree Stronglyagree

Figure 5. Responses to: I actively engage with my community leaders through their social media. Actively engaged can be considered commenting or sharing posts or direct messaging the community leader.

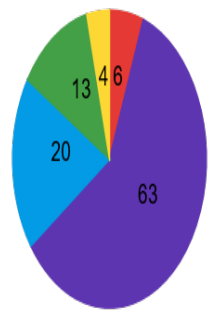

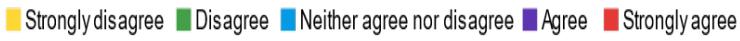

Figure 6. Reponses to: I feel more connected to my community leaders who have social media sites. 
Finally, the most surprising and telling part of these responses is that $85 \%$ of respondents stated that they agreed or strongly agreed with the statement that "If I were to see a community leader posting something I did not agree with on their personal social media page, I would be less likely to vote for them, even if I had voted for them previously.", as illustrated in Figure 2. This question deliberately stated that it was their personal page, and, therefore, may not necessarily be open to scrutiny. This result looks back at the earlier discussion of scandals caused by the use of social media by community leaders and suggests that positive posts on a personal page may not cause as much buzz.

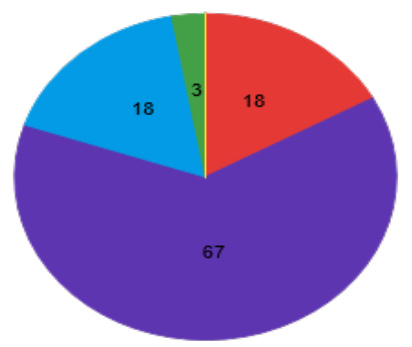

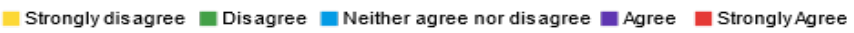

Figure 2. Responses to: If I were to see a community leader posting something I did not agree with on their personal social media page, I would be less likely to vote for them, even if I had voted for them previously

\section{Conclusions}

Overall, the research points to social media providing a feeling of connectivity between 18-24 year olds and their community leaders. However, this connectivity is more likely to cause negative effects for the community leader rather than generate positive support. This complicates the idea that social media is the best form for communicating and leads the researcher to ask the question of why social media is the main source. It is possible that the convenience is the most important part of social media, whereas websites take a few more seconds longer to access if the user knows the URL or longer if the user does not know. More research could be done to investigate the convenience of social media versus the value to society.

These results can be useful for future research on behaviors of those aged 18-24 on social media. It is also useful for community leaders who might decide to use social media. These results would suggest that it will likely do more harm than good, but more research is necessary to determine how severe a post on a personal page could affect the user's perception of the community leader. 
Finally, the researchers conclude that our hypothesis was correct in determining that the perception of community leaders was not improved through social media presence. While the responses determined that they felt more connected, this connection did not award them more trust and, in fact, the overwhelming majority responded that posts they disagree with would change that leader's ability to be re-elected or re-instated as a community leader.

\section{References}

Bode, L. (2016). Political News in the News Feed: Learning Politics from Social Media. Mass Communication and Society, 19(1), 24-48. Doi:10.1080/15205436.2015.1045149

Breuninger, K. (2018, April 2). Fox News host Laura Ingraham goes on vacation as more advertisers dump her over Parkland tweet. CNBC. Retrieved April 5, 2018, from https://www.cnbc.com/2018/04/02/fox-news-laura-ingraham-takes-vacation-as-more-advertisersdrop-her-show.html

Edgerly, S., Thorson, K., \& Wells, C. (2018). Young Citizens, Social Media, and the Dynamics of Political Learning in the U.S. Presidential Primary Election. American Behavioral Scientist, 62(8), 1042-1060. Doi:10.1177/0002764218764236

Gottfried, J., Barthel, M., Shearer, E., \& Mitchell, A. (2016). The 2016 presidential campaign: A news event that's hard to miss. Retrieved from http://www.journalism.org/2016/02/04/ the-2016presidential-campaign-a-news-event-thats-hard-to-miss/

Park, C. (2017). Do Social Media Facilitate Political Learning? Social Media Use for News, Reasoning and Political Knowledge. The Journal of Social Media in Society, 6(2), 206-238. Retrieved from http://thejsms.org/index.php/TSMRI/article/view/292

Pew Research Center. (2018, February 05). Social Media Fact Sheet. Retrieved April 05, 2018, from http://www.pewinternet.org/fact-sheet/social-media/

Smith, A., \& Anderson, M. (2018, March 01). Social Media Use in 2018. Retrieved April 05, 2018, from http://www.pewinternet.org/2018/03/01/social-media-use-in-2018/

Vossler, M. (n.d.). Newberry city commissioner under fire for posting insulting women's march meme. The Independent Florida Alligator. Retrieved January 25, 2017, from http://www.alligator.org/news/local/newberry-city-commissioner-under-fire-for-postinginsulting-women-s/article_bed8ebfc-e278-11e6-aa3b-3f1f838a5b67.html

Vromen, A., Loader, B. D., Xenos, M. A., \& Bailo, F. (2016). Everyday Making through Facebook Engagement: Young Citizens' Political Interactions in Australia, the United Kingdom and the United States. Political Studies, 64(3), 513-533. Doi:10.1177/0032321715614012 
Appendix

Survey Sample

\section{Effects of Social Media Use on Millennials' Perceptions of Community Leaders}

You are invited to participate in a research study on Effects of Social Media use on Millennials'

Perceptions of Community Leaders. This study is conducted by Dr. Cecilia E. Suarez, Professor of

Intercultural Communications and Global Leadership and Courtney Evans, who is a student at The University of Florida. Should you agree to participate, this study asks that you participate in a survey that will take approximately 5 minutes. Your decision to participate or decline participation in this study is completely voluntary and you have the right to terminate your participation at any time without penalty. There is a minimal risk that security of any online data may be breached, but our survey host (QUALTRICS) uses strong encryption and other data security methods to protect your information. Only the researchers will have access to your information on the Qualtrics server. No identifying information will be collected or connected with your responses, which will be anonymous. Findings of the project may be disseminated via written reports to University units and departments, at academic conferences, in scholarly journals, and book chapters. Participation in this research may or may not benefit you personally. There are no risks to individuals participating in this survey beyond those that exist in daily life. Additionally, there is no compensation offered for your participation in this study. If you have questions about this project, you can directly contact Dr. Cecilia E. Suarez at suarez@ufl.edu. Your decision to participate, decline, or withdraw from participation will have no effect on your current status or future relations with the University of Florida.

Please choose the statement that you most identify with according to the statement. 
Are you between the ages of $18-24$ ?

Yes (1)

No (2)

If applicable, what college or university are you currently attending? If not applicable, please put N/A.

College or university: (1)

I trust community leaders who have social media pages more than I would trust a community leader without a social media page.

Strongly Agree (1)

Agree (2)

Neither agree nor disagree (3)

Disagree (4)

Strongly disagree (5)

If I were to see a community leader posting something I did not agree with on their personal social media page, I would be less likely to vote for them, even if I had voted for them previously.

Strongly Agree (1)

Agree (2)

Neither agree nor disagree (3)

Disagree (4)

Strongly disagree (5)

Social media is my main source of information on my community leaders

Strongly agree (1)

Agree (2)

Neither agree nor disagree (3)

Disagree (4) 
Strongly disagree (5)

I prefer my community leaders to have social media sites instead of websites.

Strongly agree (1)

Agree (2)

Neither agree nor disagree (3)

Disagree (4)

Strongly disagree (5)

I actively engage with my community leaders through their social media. Actively engaged can be considered commenting or sharing posts or direct messaging the community leader.

Strongly agree (1)

Agree (2)

Neither agree nor disagree (3)

Disagree (4)

Strongly disagree (5)

I feel more connected to my community leaders who have social media sites.

Strongly agree (1)

Agree (2)

Neither agree nor disagree (3)

Disagree (4)

Strongly disagree (5)

Q7 Any additional comments?

Comment: (1) 